Коноваленко Т. Г., Каширская К. С.

Аннотация. Настоящая статья посвящена изучению манипулятивных диалогов с точки зрения различных межличностных и внеличностных установок субъектов общения. Цель исследования: выявить связь внеличностных установок и манипулятивных тактик в английском бытовом диалоге. Научная новизна исследования заключается в том, что впервые установлена связь способов манипулятивного воздействия (тактик) и внеличностных установок говорящего, предложен анализ и произведен количественный подсчёт тактик и установок. Полученные результаты показали, что искусное использование определенных ресурсов языка с целью скрытого влияния на поведенческую деятельность адресата при внеличностной установке говорящего в основном реализуется в тактиках искажения, подмены и сокрытия.

\title{
EN Relationship between Manipulative Tactics and Speaker's Extrapersonal Attitudes (by the Material of the English Everyday Dialogues)
}

\begin{abstract}
Konovalenko T. G., Kashirskaia K. S.
Abstract. The article is devoted to studying manipulative dialogues from the standpoint of various interpersonal and extrapersonal attitudes of communication subjects. The paper aims to determine relationship between extrapersonal attitudes and manipulative tactics in the English everyday dialogues. The study is novel in that it is the first to identify relationship between methods of manipulative influence (tactics) and a speaker's extrapersonal attitudes, to propose an analysis and to make a quantification of the tactics and attitudes. The attained results have shown that skilful use of certain language resources for the purpose of covertly influencing an addressee's behavioural activities with the speaker taking an extrapersonal attitude is mainly realised through tactics of distortion, substitution and concealment.
\end{abstract}

\section{Введение}

Актуальность настоящей работы определяется ее непосредственной связью с кругом проблем, очерченных современной когнитивистикой, в том числе с теорией речевого общения. Сочетание этих направлений позволит предложить новый взгляд на использование участниками общения вербальных средств языка в качестве орудия социального воздействия в акте коммуникации. Областью интересов современной лингвистики, её коммуникативно-прагматического направления, рассматривающего функционирование языковых единиц в разнообразных контекстах, является речевое манипулирование как вид воздействия, «осуществляемого путем искусного использования определенных ресурсов языка с целью скрытого влияния на когнитивную и поведенческую деятельность адресата» [13, с. 25]. Поэтому вопрос о соотношении в речевом акте установок говорящего и манипулятивных тактик представляет существенный интерес для многих ученых-лингвистов, в том числе и для нашего исследования.

Для достижения поставленной цели необходимо решить следующие задачи:

- провести исследование сущности манипулирования и выбрать классификацию манипулятивных тактик, соответствующую поставленной цели;

- установить связь манипулятивных тактик и внеличностных установок говорящего в английском бытовом диалоге, определить способы их взаимодействия;

- провести количественный подсчет результатов исследования.

Материалом для исследования послужили 120 примеров, полученных методом сплошной выборки из сценариев полнометражных английских и американских фильмов и сериалов общим объемом более 1000 страниц.

Научная статья (original research article) । https://doi.org/10.30853/phil210223

(๔ 2021 Авторы. ООО Издательство «Грамота» (๔ 2021 The Authors. GRAMOTA Publishers). Открытый доступ предоставляется на условиях лицензии СС ВY 4.0 (open access article under the CС BY 4.0 license): https://creativecommons.org/licenses/by/4.0/ 
В работе применяются следующие методы исследования: метод лингвистического описания - интерпретация микродиалогов, которая открывает путь к сознанию участников коммуникации, их идеалам и ценностям; метод семантико-синтаксического анализа; метод контекстно-семантического описания; а также метод количественного подсчета, без которого невозможна убедительная интерпретация полученных данных.

Теоретической базой исследования послужили труды В. И. Карасика [10], посвященные исследованию языковой личности и речевых актов; работы В. В. Богданова [1] и Т. Е. Добровой [7], в которых представлены важные для проводимого исследования понятия коммуникативных установок говорящего, а также труды Г. А. Копниной [13], А. Г. Гурочкиной [4], Е. Н. Шустровой [16], представляющие различные классификационные подходы в описании коммуникативных тактик.

Практическая значимость работы заключается в том, что её материалы могут быть использованы в вузах гуманитарного направления при разработке лекционных курсов «Речевая коммуникация», «Риторика», «Деловое общение» и др. Полученные результаты могут стать основой для дальнейших исследований речевых актов в рамках коммуникативно-прагматического подхода в лингвистике. Предложенные принципы описания манипулятивных тактик могут применяться при анализе коммуникативных ситуаций, протекающих в различных дискурсах: бытовом, деловом, профессиональном и т.д.

\section{Понятие манипулирования и подходы к его изучению в исследовательской литературе}

Для данного исследования важен вопрос отношения манипулирования и речевого воздействия. В современной лингвистике сформировалась точка зрения, в соответствии с которой манипулирование является разновидностью воздействия. Этого мнения придерживаются многие ученые. Так, например, указывая на непосредственную связь манипулятивных речевых действий с психикой адресата, О. Н. Быкова, определяет их как «вид языкового воздействия, используемый для скрытого внедрения в психику адресата целей, намерений, отношений или установок, не совпадающих с теми, которые имеются у адресата в данный момент» [2, с. 100].

Е. В. Денисюк понимает под манипуляцией «специфическое речевое поведение в процессе общения, направленное на побуждение собеседника совершить невыгодное для него (но выгодное для побуждающего лица) действие». Кроме того, исследователь добавляет, что основной чертой этого типа речевого поведения является скрытый характер воздействия [6, с. 66].

По мнению В. В. Дементьева, манипуляция является разновидностью непрямого воздействия, наравне с косвенным директивным иллокутивным актом [5, с. 27]; В. И. Карасик в своей работе «Языковой круг: личность, концепты, дискурс» называет это явление «одним из способов намеренного воздействия на адресата» [10, с. 67].

Е. В. Ганапольская дает определение непосредственно манипулятивному диалогу: «...диалог, осуществляемый не с целью информирования, а с целью оказания воздействия» [3, с. 6]. То есть говорящий в таком диалоге стремится, используя возможности языка, иносказательно донести адресату информацию так, чтобы навязать ему некоторое представление о действительности.

Из этих и других существующих определений постепенно сложились основные признаки, присущие манипулированию в целом и речевому манипулированию в частности, из которых Г. А. Копнина выделяет четыре основополагающих: 1) манипуляция - вид духовного, психологического воздействия, а не физическое насилие; 2) манипуляция - скрытое воздействие (конечная цель и сам факт воздействия не должны быть замечены объектом манипуляции); 3) манипуляция - это воздействие, требующее значительного мастерства и знаний; 4) человек, на которого направлена манипуляция, воспринимается не как личность, а как объект, «можно сказать, вещь» [13, с. 12]. Отталкиваясь от них, она дает наиболее емкое, на наш взгляд, определение понятию манипулирования, на которое мы будем опираться в нашем исследовании в дальнейшем: «...речевая манипуляция (манипулирование) - разновидность манипулятивного воздействия, осуществляемого путем искусного использования определенных ресурсов языка с целью скрытого влияния на когнитивную и поведенческую деятельность адресата» [Там же, с. 25].

Рассуждая о манипулятивном дискурсе, необходимо четко разграничить понятия «стратегии», «тактики» и «приемы», так как в работах, посвященных речевому манипулированию, однотипные речевые феномены манипулятивной природы ученые обозначают по-разному, смешивая эти термины либо используя другие (например, «уловки-манипуляции» в работе В. Н. Панкратова [14, с. 14]). Трудности при рассмотрении данных понятий связаны с тем, что существует «тактик великое множество, какое можно сравнить с множеством речевых действий» [15, с. 60], поэтому многие лингвисты, занимающиеся вопросами речевой манипуляции, зачастую выделяют собственные стратегии и тактики манипулирования.

Так, А. Г. Гурочкина описывает в своей статье «Манипулирование в лингвистике» три манипулятивные тактики: 1) искажение информации; 2) утаивание информации; 3) имплицитная подача. Приемы здесь не соотнесены с определенными тактиками, однако разделены между собой относительно скрываемых и нескрываемых речевых манипуляций. К первым относятся, например, замещение субъекта действия и приемы ложной аналогии, а ко вторым - использование различных тропов [4, с. 137].

Г. А. Копнина выделяет три основные манипулятивные тактики («способа»), которые отчасти перекликаются с предыдущей классификацией: 1) умолчание, то есть сокрытие определенных тем или частичное их освещение; 2) селекция информации, которая заключается в представлении адресату только той информации, которая выгодна адресату; 3) искажение информации от небольшого изменения смысла до «откровенной лжи». Причем 
последний пункт подразделяется еще на три: 1) количественные изменения; 2) передергивание информации, то есть способ подачи информации, при котором внимание привлекается к наиболее выгодному для манипулятора свойству предмета или явления; 3) переворачивание информации, то есть такой способ подачи информации, при котором высказыванию придается прямо противоположное значение. Кроме того, в исследовании описано множество приемов, которые, однако, не закреплены за определенными тактиками [13, с. 46-53].

В диссертационном исследовании Е. Н. Шустровой представлена еще одна сходная классификация, исследовательница выделяет три группы тактик: 1) сокрытие; 2) искажение; 3) подмена. Однако отличительной особенностью этой классификации является соотнесенность приемов и тактик. Так, сокрытие проявляется в умалчивании, прямом отказе от ответа (использование таких фраз, как, например, “I wouldn’t know”); в косвенном отказе от ответа или в других эксплицитных высказываниях, которые являются недостаточно информативными, например “Тhat depends”; в использовании слов неопределенной и широкой семантики, смене регистра речи и смене темы разговора, а также в селекции и смешении акцентов. Тактика искажения предполагает преувеличение и преуменьшение выражаемых оценок, эмоций, значимости событий и т.д. К группе искажения относятся скопление оценочной лексики, использование интенсификаторов, маркеров грамматического и лексического отрицания, вопросы и восклицания. Для группы подмены характерно создание ложного имиджа, так называемой языковой маски, с помощью парадоксальных ситуаций, основанных на подмене компонентов семантической структуры, а также внедрение в речь деструктивных высказываний, то есть высказываний, рассчитанных на неправильную интерпретацию адресатом [16, с. 19].

Как мы видим, все три приведенные классификации основаны на одних и тех же принципах и имеют довольно схожую структуру, в которой выделяются по три тактики. Тактики умолчания и искажения можно считать основными, так как они описаны во всех приведенных классификациях. Однако в настоящем исследовании мы будем опираться на классификацию Е. Н. Шустровой ввиду ее лаконичности и четкой соотнесенности тактик и приемов.

Кроме того, для любого акта коммуникации важно понятие коммуникативной установки говорящего, которое является одним из основных для нашего исследования. Из всех существующих в научной литературе описаний коммуникативных установок нам представляется наиболее оптимальным определение, предложенное В. В. Богдановым - Т. Е. Добровой (установка - это то, что находится в центре внимания говорящего), и их классификация на межличностные (на себя, на адресата и на третьих лиц) и внеличностные (на действительность и языковые средства) установки. Следует сразу оговориться, что проведенный анализ образцов диалогов с межличностными установками не входит в содержание данной статьи и частично уже являлся предметом других публикаций $[11 ; 12]$.

\section{Взаимосвязь между типом установки и манипулятивными тактиками}

\section{1. Манипулирование при установке на действительность}

Напомним, что под внеличностными установками по классификации В. В. Богданова - Т. Е. Добровой понимаются установки на действительность (которые включают в себя установку на пропозициональное содержание) и на языковые средства. Количество найденных нами примеров с внеличностными установками гораздо меньше количества примеров с межличностными установками - около 34\% от всего количества собранных диалогов (41 из 120). Далее в данном пункте будут рассматриваться примеры с установкой на действительность, т.е. те манипулятивные диалоги, в которых речь идет о каком-либо предмете, явлении, ситуации или пространственно-временных параметрах.

Для манипулятивных диалогов с внеличностными установками говорящего установка на действительность оказалась гораздо более употребительной, чем установка на языковые средства - она используется приблизительно в 80,5\% случаев (33 из 41).

Все примеры с установкой на действительность можно условно разделить на 4 группы: установка на действительность и себя, на действительность и адресата, только на действительность, на действительность и третьих лиц (группы примеров расположены по частотности).

Сочетание установки на действительность и себя стало самым распространенным - примерно 39\% от всех примеров с внеличностными установками (16 из 41). Для данной группы манипулятивных диалогов наиболее характерна группа тактик искажения (9 из 16 примеров, 56\%), ее можно рассмотреть на следующем примере:

(1) Норма Луиза - чересчур заботливая и эгоистичная мать-одиночка, Норман - замкнутый подросток, ее любимый сын. Они только что переехали в другой город и купили мотель. В новой школе Норману предложили стать частью спортивной команды (на которую ему придется тратить много времени), и для этого его матери необходимо подписать официальное согласие. Однако Норма не привыкла к тому, что ее сын проводит время не с ней, и потому заставляет его отказаться от предложения.

NORMA LOUISE: Norman, we just bought a MOTEL. How do you think I'm going to get it up and running without your help? I mean, really. You're putting me in a tough spot.

NORMAN: Mom, it's okay. I don't have to do it [17].

Здесь Норма сначала делает акцент на ситуации в целом (они только что купили мотель), а потом на себе, говоря о том, как ей будет тяжело. Манипулируя сыном, она использует прием искажения, который выражается в преувеличении ее состояния с помощью интенсификатора “really” и окрашенной лексики “tough spot”. 
Незначительно реже в примерах с установкой на себя и на действительность была использована группа тактик сокрытия (7 примеров из 16,43\%), как, например, в следующем диалоге:

(2) Адриана - преступница, она украла ребенка и требует за него выкуп в виде бриллиантов, которые у нее якобы забрали родители этого ребенка. Джейн - детектив, он пытается заставить Адриану выдать полиции ребенка, предлагая ей взамен фальшивые бриллианты.

ADRIANNA: How do I know those are real diamonds?

JANE: I don't know. They look real to me. Here, have a look at them [21].

Манипулируя Адрианой, Джейн говорит о бриллиантах и о себе. Группа тактик сокрытия в его реплике реализуется с помощью прямого отказа от ответа на конкретный вопрос: “I don't know” - и недостаточно информативного высказывания: “Тhey look real to me”. Этой фразой он заставляет преступницу отвлечься и внимательно оценить бриллианты, давая полиции возможность забрать ребенка.

Вторую по частотности группу манипулятивных диалогов с внеличностными установками составляют диалоги с установками на действительность и адресата - 32\% (13 из 41). Среди них также встречаются группы тактик искажения и сокрытия, и для данной группы примеров, так же как и для манипулятивных диалогов с межличностной установкой на адресата, характерно преобладание группы тактик искажения (8 из 13,61\%). Более подробно рассмотрим это на следующем примере:

(3) Тайлер манипулирует Джеком, пытаясь навязать ему свой образ мышления и свои идеи, заставить его отказаться от всех материальных ценностей, пересмотреть свой взгляд на жизнь.

TYLER: Listen to me. You have to consider the possibility that God doesn't like you, he never wanted you. In all probability, he hates you. This is not the worst thing that can happen...

TYLER: We don't need him...

JACK: We don't [20]?..

В этом диалоге Тайлер в первую очередь говорит о Боге - нами решено было считать Бога явлением и, соответственно, установкой на действительность - и его взаимоотношении с адресатом. В процессе манипуляции говорящий использует тактику искажения, которая выражается в данном случае с помощью интенсификатора “never”, маркеров отрицания: “doesn’t like”, “don’t need”, “not the worst thing”, эмоционально окрашенной лексики: “hates”.

Несколько реже в примерах данной группы можно встретить группу тактик сокрытия (5 из 13,38\%). Подробнее рассмотрим ее на следующем примере:

(4) Кэтрин и Себастьян заключили пари, по которому Себастьян должен соблазнить их общую знакомую. В случае выцгрыша Кэтрин получает красный Порш, в случае проигрыша она должна будет провести ночь с Себастьяном. Однако это пари - лишь часть ее плана, и ей необходимо, чтобы Себастьян выиграл, потому она манипулирует им, пытаясь спровоцировать.

KATHRYN: And that's why you're losing your bet?

SEBASTIAN: I'm not losing the bet. It's just taking longer than I expected.

KATHRYN: Do you mind if I take my new Porsche for a ride?

SEBASTIAN: Kathryn, the only thing you're going to be riding is me. Now if you'll excuse me, I have some work to do [18].

В своих манипулятивных высказываниях Кэтрин говорит об автомобиле и о Себастьяне, своем собеседнике, адресате. Манипуляция здесь строится на приеме резкой смены темы разговора: неожиданно для собеседника Кэтрин вставляет просьбу прокатиться на Порше, уже называя его своим, хотя она его еще не выиграла. Таким образом, она выводит адресанта из себя и заставляет его еще больше стремиться к выигрышу в споре.

Следующей по частотности группой являются примеры с установкой только на действительность они составили примерно 21\% всех собранных примеров с внеличностной установкой (9 из 41). В отличие от двух предыдущих групп в этих диалогах наиболее часто употребляется группа тактик подмены (она была использована в 9 из 9 примеров), выражающейся в основном в подмене понятий. В примерах данной группы говорящий чаще всего затрагивает в своей речи абстрактные понятия или общеизвестные факты, представляя их адресату в неожиданном для него ключе:

(5) Тайлер манипулирует Джеком, пытаясь навязать ему свой образ мышления и свои идеи, заставить его отказаться от всех материальных ценностей, пересмотреть свой взгляд на жизнь. Разговор идет в автобусе, герои обсуждают большой рекламный плакат Calvin Klein.

JACK: I feel sorry for all the guys packing into gyms, trying to look like Calvin Klein and Tommy Hilfiger said they should.

TYLER: Self-improvement is masturbation. Self-destruction is the answer [20].

В этом случае манипуляция происходит исключительно с помощью тактики подмены, реализующейся с помощью подмены понятий. Рассуждая об абстрактных понятиях, герой совершенно очевидно подменяет хорошее плохим, буквально называя саморазвитие мастурбацией, а саморазрушение - необходимым решением.

Похожую ситуацию мы наблюдаем в следующем примере, с той лишь разницей, что на этот раз две группы манипулятивных тактик, искажение и подмена, используются совместно.

(6) Тайлер обращается к Джеку и другим членам бойщовского клуба, манипулирует ими, стараясь навязать им свое мировоззрение и заставить выполнять то, что он приказывает. 
TYLER: Advertisements have them chasing cars and clothes, working jobs they hate so they can buy shit they don't need. We are the middle children of history, with no purpose or place. We have no great war, or great depression. The great war is a spiritual war, the great depression is our lives. We were raised by television to believe that we'd be millionaires and movie gods and rock stars - but we won't. And we are learning this fact. And we are very pissed-off [Ibidem].

Манипуляция Тайлера в данном случае строится вокруг явлений современного мира или общеизвестных суждений, причем в этом диалоге наблюдается подмена понятий: так, например, саму жизнь он называет Великой Депрессией. Основа же манипуляции здесь приходится на группу тактик искажения, проявляющуюся в использовании оценочной лексики: “hate”, “shit”, “pissed-off”; маркеров отрицания: “don't need”, “no purpose or place”, “no great war”, “we won't”.

Самой малочисленной группой среди всех примеров с установкой на действительность стали диалоги с установкой на действительность и на третьих лиц - 7\% (3 из 41). В данном случае все три группы манипулятивных тактик используются примерно в равной степени.

(7) Джейн - детектив, Вагнер - убийца, который был психоаналитиком жертвы, Таннена. Чтобы доказать, что Вагнер виновен, Джейн хочет заманить его в кабинет Таннана, который является местом преступления, выдумав историю про личный дневник жертвы.

JANE: Do you recall we were talking about Tannen the other day? You said that he kept a diary...

WAGNER: No.

JANE: But there was no diary among his effects... Sorry, no?

WAGNER: You had it wrong. I said he didn't keep a diary.

JANE: Strange. Then it must have been someone else who told me. Either that, or I'm going mad. Because I definitely, $100 \%$ remember that Tennen kept a diary.

WAGNER: That is strange. But why does it matter if he kept a diary?

JANE: You're right. It doesn't matter... Only I was thinking, you know why magicians have beautiful girl assistants?

WAGNER: Why?

JANE: They are reliable distractors of attention. Anyhow, I'll send over a couple of CSI techs tomorrow to search his office.

WAGNER: Didn't they already search his office?

JANE: Oh, they never do it thoroughly the first time. One more for luck, yeah? It must be there somewhere [21].

Манипулируя Вагнером, Джейн говорит о дневнике жертвы - в этом выражается установка на действительность, а также об ассистентках и криминалистах, то есть о третьих лицах. На данном примере можно рассмотреть сочетание групп тактик подмены и искажения. Подмена выражается здесь созданием парадоксальной ситуации: Джейн намеренно подменяет информацию об отсутствии дневника ложной информацией о его наличии. Он также вводит деструктивное высказывание: “It doesn't matter”, что тоже является приемом подмены. Искажение в данном случае проявляется в использовании окрашенных слов “mad”, “strange”, маркеров отрицания “never” и преувеличения “must have been”, “definitely”, “must be”.

\section{2. Манипулирование при установке на языковые средства}

Как уже упоминалось выше, из всех собранных нами примеров с внеличностными установками говорящего диалоги с установкой на языковые средства встречаются в 19,5\% случаев (8 из 41 диалога), то есть гораздо реже, чем диалоги с установкой на действительность. Под установкой на языковые средства мы понимаем ситуацию, в которой говорящий использует определенные средства языка, включающие в себя стиль речи говорящего, использование диалектов, жаргона, устаревших слов и выражений и иностранный код, а также ситуацию, где говорящий непосредственно обсуждает выбранные им, адресатом или слушающим языковые средства.

В отличие от диалогов с установкой на действительность, примеры с установкой на языковые средства не встретились нам обособленно. Они употребляются только в сочетании с различными видами межличностных установок: на себя, на адресата и на третьих лиц. Далее рассмотрим каждый случай по порядку:

(8) Лоуренс - профессиональный жиголо, он живет на средства богатых женщин. В данном разговоре с богатой американкой по имени Фанни он притворяется гордым, но бедным принцем маленькой европейской страны, который отчаянно нуждается в деньгах на благо его страны.

LAWRENCE: - Are you one of my subjects?

FANNY: No, I'm an American. Fanny Eubanks of Omaha. If you're in trouble, and if I can help.

LAWRENCE: Thank you. But I cannot accept. You've risked too much just in speaking to me [19].

Установка на языковые средства в этом примере выражена тем, что, манипулируя Фанни, Лоуренс нарочито использует возвышенную лексику, характерную для его образа горделивого принца: “subject”, “cannot accept”, что заставляет девушку поверить ему; при этом в центре внимания говорящего находится он сам, тем самым реализуя установку на себя. В данном случае наблюдается использование приема подмены, выраженного в создании языковой маски, а также приема искажения, выраженного в использовании интенсификатора “too much” для преувеличения состояния говорящего.

Также особо стоит отметить примеры диалогов с установкой на языковые средства и себя (3 из 8 диалогов - 37,5\%), в которых прием языковой маски реализуется говорящим с помощью использования иностранного кода, то есть в таких ситуациях герой притворяется иностранцем. В ходе нашего исследования мы обнаружили два таких примера. Рассмотрим один из них более подробно:

(9) Лоуренс говорит с немецким акцентом, чтобы Дженет приняла его за известного немецкого врачапсихиатра и заплатила ему крупную сумму денег за лечение своего знакомого. 
JANET: Are you Dr. Schuffhausen?

LAWRENCE: Yes, Fraulein.

JANET: What a coincidence! This is a miracle. I just wrote you about someone who needs help.

LAWRENCE: Good. I look forward to reading it when I get back to my clinic.

JANET: What?

LAWRENCE: Goodbye. Auf Wiedersehen [Ibidem].

В данном диалоге установка на языковые средства проявляется в использовании немецких слов: “Fraulein”, “Auf Wiedersehen”. В этом же выражается прием создания языковой маски, входящий в группу тактик подмены. Установка на себя в этом случае реализуется в том, что герой говорит в процессе манипуляции о себе.

Помимо межличностной установки на себя, диалог с установкой на языковые средства может сочетаться с межличностной установкой на адресата, что может быть рассмотрено на примере:

(10) Кэтрин и Себастьян - сводные брат и сестра. Кэтрин хочет заставить Себастьяна расстаться с девушкой, которую он полюбил.

KATHRYN: Oh my God! You're completely p-whipped.

SEBASTIAN: No, I'm not.

KATHRYN: P-whipped, p-whipped.

SEBASTIAN: What's wrong with you? Why are you acting this way?

KATHRYN: (starts to cry) I'm sorry. It's just upsetting. You're in love with her. You don't love me anymore [18].

Манипулирование Кэтрин строится вокруг сленгового слова “p-whipped”, которое означает “подкаблучник”, что реализует установку на языковые средства, при этом она использует это слово в отношении Себастьяна - в этом выражается установка на адресата. В приведенном примере используются приемы тактики искажения: оценочная лексика “completely”, восклицание “Oh my God!”.

Среди диалогов с внеличностной установкой на языковые средства и на адресата (4 из 8 диалогов - 50\%) нам встретились примеры, в которых говорящий не просто подбирает определенную лексику или диалект, а рассуждает непосредственно о словах, произнесенных адресатом:

(11) Джейн и Майк - пара, они оба работают в Кембриджском университете. Джейн считает себя умнее и выше Майка по статусу, потому думает, что может помыкать им и заставлять делать то, что она хочет, иговорить так, как она хочет. Диалог происходит по пути на коктейльную вечеринку, Джейн опасается, что Майк ее опозорит.

JANE: Do you think there might be a chance that once your thesis has been read you'll start talking 'proper English?'

MIKE: 'D’you mean?'

JANE: ‘All this “cool” and "slamming” and "woah”... what's it all about? You'll probably be a fellow of the college next year. Do you think Trevor Roper used to go around the place saying “woah, man... like, cool.” I mean, darling, it's so strange. So decidedly odd' [21].

В данном случае героиня одновременно говорит о лексиконе Майка и о самом Майке, то есть реализуются установки на языковые средства и на адресата. Манипулирование здесь совершается с помощью использования тактики искажения, выражаемой через преувеличение с помощью окрашенных слов “proper English”, "strange", “decidedly odd”.

Сочетание установки на языковые средства и третьих лиц было реализовано лишь в одном примере (что составляет $12,5 \%$ ):

(12) Лоуренс уже добился того, что мисс Трамбл отдала ему огромную сумму денег, и, чтобы избежать женитьбы на ней, обращается к Фредди, который притворяется умственно отсталым братом Лоуренса, Рупрехтом, чтобы отпугнуть женщину.

LAWRENCE: Now, I want you to meet this nice lady.

MISS TRUMBLE: Hello, Rupreht.

FREDDIE: Mother?

LAWRENCE: This isn't your mother.

FREDDIE: Not Mother?

LAWRENCE: But I have wonderful news. Miss Trumble and I are going to be married. We're going to live in Oklahoma.

FREDDIE: Oklahoma-oma-oma-ma [19].

В данном случае наблюдается установка на слушающего - мисс Трамбл является объектом манипуляции, хотя сама манипуляция осуществляется в диалоге Лоуренса и Фредди. Фредди намеренно говорит очень просто, имитируя речь умственно отсталого. Здесь реализуется группа тактик подмены: используя простую лексику и повторение слогов, герой использует прием создания языковой маски.

Анализ взаимодействия манипулятивных тактик и различных установок говорящего показал, что для всех манипулятивных диалогов в целом наиболее распространенной является группа тактик искажения. Во внеличностных установках на действительность в сочетании с установками на себя, адресата, третьих лиц и слушающих группа тактик сокрытия использовалась чаще подмены. Группа тактик подмены также стала наиболее характерной для примеров с внеличностными установками только на действительность (при этом чаще всего она проявлялась в использовании приема подмены понятий) и на языковые средства. Кроме того, для примеров с установкой на языковые средства и их комбинации использовались тактики искажения и подмены.

Количественные данные, полученные в результате исследования взаимодействия коммуникативных тактик и внеличностных установок говорящего в английском бытовом диалоге, приведены в Таблице 1. 
Таблица 1. Количественные данные, полученные в результате исследования

\begin{tabular}{|c|c|c|c|c|}
\hline & Установки* & \multicolumn{3}{|c|}{ Группы тактик ${ }^{* *}$} \\
\hline \multicolumn{2}{|c|}{ Внеличностные установки (всего 35\%) } & Искажение & Подмена & Сокрытие \\
\hline \multirow{4}{*}{$\begin{array}{l}\text { на действительность } \\
(80,5 \%)\end{array}$} & только на действительность (21\%) & 0 & 100 & 0 \\
\hline & на действительность и себя (39\%) & 56 & 0 & 43 \\
\hline & на действительность и адресата (32\%) & 61 & 0 & 38 \\
\hline & на действительность и третьих лиц (7\%) & 34 & 33 & 33 \\
\hline \multirow{3}{*}{$\begin{array}{l}\text { на языковые средства } \\
(19,5 \%)\end{array}$} & на языковые средства и себя $(37,5 \%)$ & 50 & 50 & 0 \\
\hline & на языковые средства и адресата (50\%) & 0 & 100 & 0 \\
\hline & на языковые средства и третьих лиц $(12,5 \%)$ & 0 & 100 & 0 \\
\hline
\end{tabular}

*Процент считался от количества примеров межличностных (79) и внеличностных (41) установок говорящего.

***Процент считался от количества примеров каждой установки или сочетания установок.

\section{Заключение}

Таким образом, в рамках проведенного исследования были сделаны следующие выводы.

1. Манипулирование представляет собой сложный конструкт, разновидность воздействия, осуществляемого путем искусного использования определенных ресурсов языка с целью оказания скрытого влияния на адресата, а именно создания мотивации к совершению нужного манипулятору действия, формирования у объекта речевого воздействия убежденности в выгодности или необходимости этого действия. Указанный тип воздействия осуществляется с помощью манипулятивных тактик. Проанализировав несколько классификаций манипулятивных тактик, мы остановились на классификации Е. Н. Шустровой, соответствующей поставленной нами цели, в которой выделяются группы тактик искажения, подмены и сокрытия.

2. При анализе коммуникативных установок мы обнаружили, что в бытовом диалоге внеличностные установки употребляются гораздо реже, чем межличностные, и составляют только 34\% от всех собранных примеров. При этом установка на действительность оказалась более употребительной, чем установка на языковые средства. Кроме того, внеличностные установки говорящего крайне редко используются обособленно, большая часть собранного материала приходится на комбинации внеличностных и межличностных установок.

3. Выявлены закономерности в сочетании манипулятивных тактик и внеличностных установок говорящего в бытовом английском диалоге:

- $\quad$ тактики искажения обнаружены при любых установках говорящего и их комбинациях и превосходят по количеству все остальные тактики;

- $\quad$ тактики подмены использовались при установке на действительность, действительность и третьих лиц и во всех установках, использующих языковые средства;

- тактики сокрытия характерны только для комбинации установок на действительность и себя, действительность и адресата, действительность и третьих лиц.

4. В настоящее время проблема языкового манипулирования, хотя и является одной из самых актуальных среди лингвистических исследований, продолжает оставаться недостаточно изученной. С одной стороны, потому что истинные мотивы и цели манипулятора не всегда возможно подвергнуть адекватной оценке, т.к. они остаются вне зоны сознания объекта манипуляции, с другой - эффективность манипулятивных тактик можно оценить только в случае детального рассмотрения ситуации, в которой происходит общение, а итог может оказаться отложенным или растянутым во времени. Перспективы дальнейших исследований видятся в продолжении изучения речевой манипуляции в различных дискурсах: бытовом, официально-деловом, профессиональном, юридическом и т.д.; сопоставительном описании тактик в указанных дискурсах и лингвокультурах.

\section{Источники | References}

1. Богданов В. В. Речевое общение. Прагматические и семантические аспекты: учебное пособие. Л.: Лгу, 1990. $88 \mathrm{c.}$

2. Быкова О. Н. Языковое манипулирование // Теоретические и прикладные аспекты речевого общения. Вестник Российской риторической ассоциации / Краснояр. гос. ун-т; под ред. А. П. Сковородникова. Красноярск, 1999. Вып. 1 (8). С. 99-103.

3. Ганапольская Е. В. Воздействие диалогической речи на адресата // Речевое общение: искусство убеждать / сост. Н. В. Анисина и др. СПб.: Изд-во С.-Петерб. гос. ун-та, 1999. С. 78-110.

4. Гурочкина А. Г. Манипулирование в лингвистике // Известия Российского государственного педагогического университета им. А. И. Герцена. Серия «Общественные и гуманитарные науки». 2003. Т. 3. № 5. С. 136-141.

5. Дементьев В. В. Основы теории непрямой коммуникации: автореф. дисс. ... к. филол. н. Саратов, 2001. 38 с.

6. Денисюк Е. В. Феномен манипуляции: речедеятельностная интерпретация // Культурно-речевая ситуация в современной России: вопросы теории и образовательных технологий: тезисы докладов и сообщений Всероссийской науч.-метод. конф. (г. Екатеринбург, 19-21 марта 2000 г.) / под ред. И. Т. Вепревой. Екатеринбург: Изд-во УРГПУ, 2000. С. 66-68. 
7. Доброва Т. Е. Особенности речевых актов англоязычной рекламы китайских интернет-магазинов // Вестник Санкт-Петербургского университета. Серия 9. Филология, востоковедение, журналистика. 2014 . Вып. 1. C. $131-135$.

8. Иссерс О. С. Коммуникативные стратегии и тактики русской речи. Изд-е 5-е. М.: ЛКИ, 2008. 288 с.

9. Иссерс О. С. Паша-«Мерседес», или Речевая стратегия дискредитации // Вестник Омского университета. 1997. Вып. 2. С. 51-54.

10. Карасик В. И. Языковой круг: личность, концепты, дискурс. Волгоград: Перемена, 2002. 477 с.

11. Каширская К. С., Поспелова А. Г. Влияние межличностных установок на выбор манипулятивных тактик в английском диалоге [Электронный ресурс]. URL: https://moluch.ru/archive/145/40775/ (дата обращения: 11.04.2021).

12. Коноваленко Т. Г., Пятницкая А. С. Манипулирование как один из способов ведения деловой беседы [Электронный ресурс] // Научная весна - 2020. Гуманитарные науки: сборник научных трудов: научное электронное издание. Шахты: ИСОиП (филиал) ДГТУ в г. Шахты, 2020. C. 29-34. URL: https://www.sssu.ru/ Portals/0/2020/doc/Сборник Научная Весна 2020_гум.науки.pdf (дата обращения: 28.04.2021).

13. Копнина Г. А. Речевое манипулирование: учебное пособие. М.: Наука; Флинта, 2007. 176 с.

14. Панкратов В. Н. Манипуляции в общении и их нейтрализация: практическое руководство. М.: Изд-во Института психотерапии, 2001. 208 с.

15. Формановская И. Н. Речевое общение: коммуникативно-прагматический подход. М.: Русский язык, 2002. 216 с.

16. Шустрова Е. Н. Лингвистическая интерпретация стратегии мистификации в англоязычном речевом общении: автореф. дисс. ... к. филол. н. СПб., 2008. 21 с.

17. Bates Motel [Электронный ресурc]. URL: http://www.springfieldspringfield.co.uk/episode_scripts.php?tvshow=bates-motel (дата обращения: 05.03.2021).

18. Cruel Intentions [Электронный ресурс]. URL: http://www.dailyscript.com/scripts/cruel-intentions.html (дата обращения: 05.04.2021).

19. Dirty Rotten Scoundrels Script [Электронный ресурc]. URL: http://www.script-o-rama.com/movie_scripts/ d/dirty-rotten-scoundrels-script-transcript.html (дата обращения: 05.04.2021).

20. http://www.dailyscript.com/scripts/taking_lives.pdf (дата обращения: 28.04.2021).

21. https://thebakerboy.ucoz.com/load/scripts/the_mentalist_draft_pilot_part_2/2-1-0-65 (дата обращения: 28.04.2021).

\section{Информация об авторах | Author information}

RU Коноваленко Татьяна Георгиевна ${ }^{1}$, к. филол. н., доц. Каширская Ксения Сергеевна ${ }^{2}$

${ }^{1}$ Институт сферы обслуживания и предпринимательства (филиал)

Донского государственного технического университета, г. Шахты

EN Konovalenko Tatiana Georgievna ${ }^{1}, \mathrm{PhD}$

Kashirskaia Kseniia Sergeevna ${ }^{2}$

${ }^{1}$ Institute of the Service Sector and Entrepreneurship (branch) of DSTU, Shakhty, Rostov Region

${ }^{1}$ kaschirochka@mail.ru, ${ }^{2}$ ksenia.kashirskaya@mail.ru

\section{Информация о статье | About this article}

Дата поступления рукописи (received): 06.04.2021; опубликовано (published): 31.05.2021.

Ключевые слова (keywords): коммуникация; манипулирование; межличностные и внеличностные установки; речевые тактики; communication; manipulation; interpersonal and extrapersonal attitudes; speech tactics. 